Check for updates

Cite this: RSC Adv., 2019, 9, 41010

\title{
A comprehensive review on the prevalence, pathogenesis and detection of Yersinia enterocolitica
}

\author{
Muhammad Shoaib, (DD abd Aamir Shehzad, ${ }^{\text {cd }}$ Husnain Raza, (D) ad Sobia Niazi, ${ }^{\text {ad }}$ \\ Imran Mahmood Khan, ${ }^{\text {abd }}$ Wasim Akhtar, ${ }^{\text {b }}$ Waseem Safdar ${ }^{\text {e }}$ and Zhouping Wang (D) *ab
}

Food safety is imperative for a healthy life, but pathogens are still posing a significant life threat. "Yersiniosis" is caused by a pathogen named Yersinia enterocolitica and is characterized by diarrheal, ileitis, and mesenteric lymphadenitis types of sicknesses. This neglected pathogen starts its pathogenic activity by colonizing inside the intestinal tract of the host upon the ingestion of contaminated food. $Y$. enterocolitica remains a challenge for researchers and food handlers due to its growth habits, low concentrations in samples, morphological similarities with other bacteria and lack of rapid, costeffective, and accurate detection methods. In this review, we presented recent information about its prevalence, biology, pathogenesis, and existing cultural, immunological, and molecular detection approaches. Our ultimate goal is to provide updated knowledge regarding this pathogen for the development of quick, effective, automated, and sensitive detection methods for the systematic detection of $Y$. enterocolitica.

Received 2nd September 2019 Accepted 31st October 2019

DOI: $10.1039 / \mathrm{c} 9 \mathrm{ra06988g}$

rsc.li/rsc-advances the US caused by $Y$. enterocolitica infections, and $90 \%$ of these are foodborne. ${ }^{7,8}$ The diverse geographical distribution is the primary cause of the global epidemic of Yersiniosis, ${ }^{\mathbf{1}, \mathbf{9}}$ as shown in Fig. 1.

The transmission of $Y$. enterocolitica occurs during blood transfusions, through which it causes the highest cases of mortality. ${ }^{\mathbf{1 0 , 1 1}}$ The primary sources of this bacterium are animaloriginated foods, especially pork and pork products. The propagation of $Y$. enterocolitica at low temperatures has marked it as a life-threatening bacterium; hence, it has been linked with foodborne infections. Some studies have revealed that it can also survive and reproduce in vacuum packaging and refrigerated foods. ${ }^{12-15}$ Food-based Yersiniosis epidemics are linked with multiple food items, including dairy, ${ }^{13}$ meat, ${ }^{16,17}$ poultry, fruits, vegetables, stewed and fermented products and also seafoods, ${ }^{18,19}$ as given in Fig. 2. The infective dose of $Y$. enterocolitis is about $10^{4}-10^{6} \mathrm{CFU} \mathrm{mL}{ }^{-1}$ for human infections, ${ }^{20}$ which has not been investigated in previous studies.

In 1976, the first outbreak of Yersiniosis was reported in New York due to the consumption of $Y$. enterocolitica-contaminated chocolate milk. Similar outbreaks of milk-borne Yersiniosis were also reported in other parts of the United States, Europe, Australia, Sweden and India. ${ }^{21}$ Subsequently, several outbreaks of Yersiniosis caused by eating contaminated pork products were reported in Hungary, ${ }^{22}$ United States, Norway, China, and European countries. ${ }^{19}$ Frequent cases of Yersiniosis in European countries are rarely associated with beef, mutton, milk and dairy products; $;^{9,23-26}$ therefore, the distribution of $Y$. enterocolitica is highly diverse as it can contaminate both animal and 
plant-based foods, thus triggering an alarming situation of foodborne illness for the food authorities. Yersiniosis has been reported several times in the past few years around the globe; however, the source of infection has remained unknown ${ }^{27}$ in most of these cases.

$Y$. enterocolitica can survive and grow in contaminated foods, both at the industrial and commercial levels. The latest trend of the increased consumption of processed foods has further enhanced the risk of Yersiniosis. Moreover, the global emergence of Yersiniosis is also linked with the growth of international food trade, the revolution of animal husbandry and the development of the food processing industry. ${ }^{28}$ The Foodborne Diseases Active Surveillance Network (Food Net, USA) studied the emergence of Yersiniosis for about ten years (1996-2007) and concluded that the cases of Yersiniosis in the United States were miscalculated due to the lack of detection methods. On the other hand, in a few other countries, food samples are not considered for $Y$. enterocolitica, which indicates that the diagnosis is inadequate. ${ }^{29,30}$ A timely and adequate detection of $Y$. enterocolitica in food samples is highly recommended in order to prevent the distribution of this pathogen. Therefore, updated information about the morphology, classification, sources of infection, pathogenicity, and cultural and molecular detection methods is summarized in this review, which will serve as a guideline for researchers and highlight the key research areas for the development of rapid detection methods.

\section{Sources, classification, and biology}

$Y$. enterocolitica is a rod-shaped facultative anaerobic, nonspore-forming Gram-negative bacterium habitually found in nature, including food, water, and animals. However, pigs are considered as the main reservoirs. ${ }^{31}$ It is estimated that $35-70 \%$ of swine herds and 45-100\% of individual pigs carry $Y$. enterocolitica. According to pathogenicity and geographical distribution, it is categorized into five distinct groups: $1 \mathrm{~A}, 1 \mathrm{~B}, 2,3,4$, 5. Y. enterocolitica has about 60 serotypes. Some serogroups belong to each biota as follows: $1 \mathrm{~A}(\mathrm{O}: 5 ; \mathrm{O}: 6,30$; O:7, 8; O:18; O:46), 1B (O:8; O:4; O:13a, 13b; O:18; O:20; O:21), 2 (O:9; O:5, 27), 3 (O:1, 2, 3; O:5, 27), 4 (O:3) and 5 (O:2,3). ${ }^{32,33}$ The

Muhammad Shoaib obtained masters degree in Food Science and Technology from the University of Agriculture Faisalabad, Pakistan and is currently pursuing PhD degree in Food Science and Technology at Jiangnan University, China. Due to his excellent academic record, he obtained the Full-time Chinese government scholarship and won the Presidential scholarship twice at the Jiangnan University. His main research area is food safety; currently, he is working on novel detection methods of pathogens. His recent project is about the selection of aptamers against pathogens and their applications in combination with functional nanomaterials for detection. His contribution in the field of science is in the form of 30 publications in well-renowned journals with 206 citations. predominant serogroups that cause the most infections are $\mathrm{O}: 3$, O:8, O:9, and O:5. ${ }^{\mathbf{8} 28}$ Some of the biochemical features are described in Table 1.

The biphasic lifestyle of $Y$. enterocolitica allows it to grow within or outside the human body. It produces pinpoint colonies and shows slow growth on sheep blood agar, MacConkey agar, and Hektoen enteric-coated agar plates. The selective isolation was reported on Y. enterocolitica cefsulodinIgasanovobimycin (CIN) and virulent Y. enterocolitica (VYE) agar plates. $Y$. enterocolitica can grow at both low and high temperatures ranging from 0 to $44{ }^{\circ} \mathrm{C}$, but $25-30{ }^{\circ} \mathrm{C}$ is considered as the optimum growth range. The growth temperature also affects the physiology of the bacterial cells. A study revealed that at lower temperatures, it becomes motile due to the growth of peritrichous flagella and more virulent due to the transcription of virulent factors like ystA, enterotoxin production gene ail, and invasion of locus gene, $r f b C$, and O-antigen genes, ${ }^{34}$ while at higher temperatures, it becomes non-motile and lacks flagella. Besides, it can even grow at $1{ }^{\circ} \mathrm{C}$ in milk and raw meat in a $5 \%$

Dr Wang was born in April 1974 in Shaanxi, China. In 2004, he obtained his PhD degree in Analytical Chemistry and the research involved luminescence-based systematic analysis. Later on, he completed his postdoctoral research at Tsinghua University in Beijing, China. In July 2006, Dr Wang joined the School of Food Science and Technology at Jiangnan University and also worked as a high-grade researcher for the State Key Laboratory of Food Science and Technology at Jiangnan University. Currently, Dr Wang is the Vice Dean of the School of Food Science and Technology and the Director of the Research Center of Food Safety and Quality at Jiangnan University, besides being a Professor and doctoral supervisor. Meanwhile, Dr Wang has received the following awards: Leading Talents of National "Ten thousand plan", Youth Science and Technology Innovation Leader of Ministry of Science and Technology, the New Century Talents of the Ministry of Education, France bioMerieux Science Fund Winner, Distinguished Professor of Jiangsu Province, the first batch food safety experts of catering service of CFDA, Vice President of Food Quality and Safety Instrumentation and Technology Application Branch of Chinese Society of Instrumentation, Food Safety Standards Evaluation Experts of Jiangsu Province, Secretary-General of Institute of Food Science and Technology of Jiangsu Province, "Six Talent Peaks" of Jiangsu Province, "333 Talents Project”, etc. Dr Wang has mentored more than 50 graduate students, published 157 original research papers and obtained 22 authorized invention patents of China. Dr Wang is also serving as a member of the editorial board of two international journals named "Aptamer" and "Aptamer \& Synthetic Antibodies". Dr Wang's research work is mainly focused on the development of recognition molecules, aptamers for bioassays of food safety hazard factors (especially for foodborne pathogens and mycotoxins), nano-probe-based biosensors, nanomaterial synthesis and use of aggregationinduced emission probes for bioimaging and sensing. 


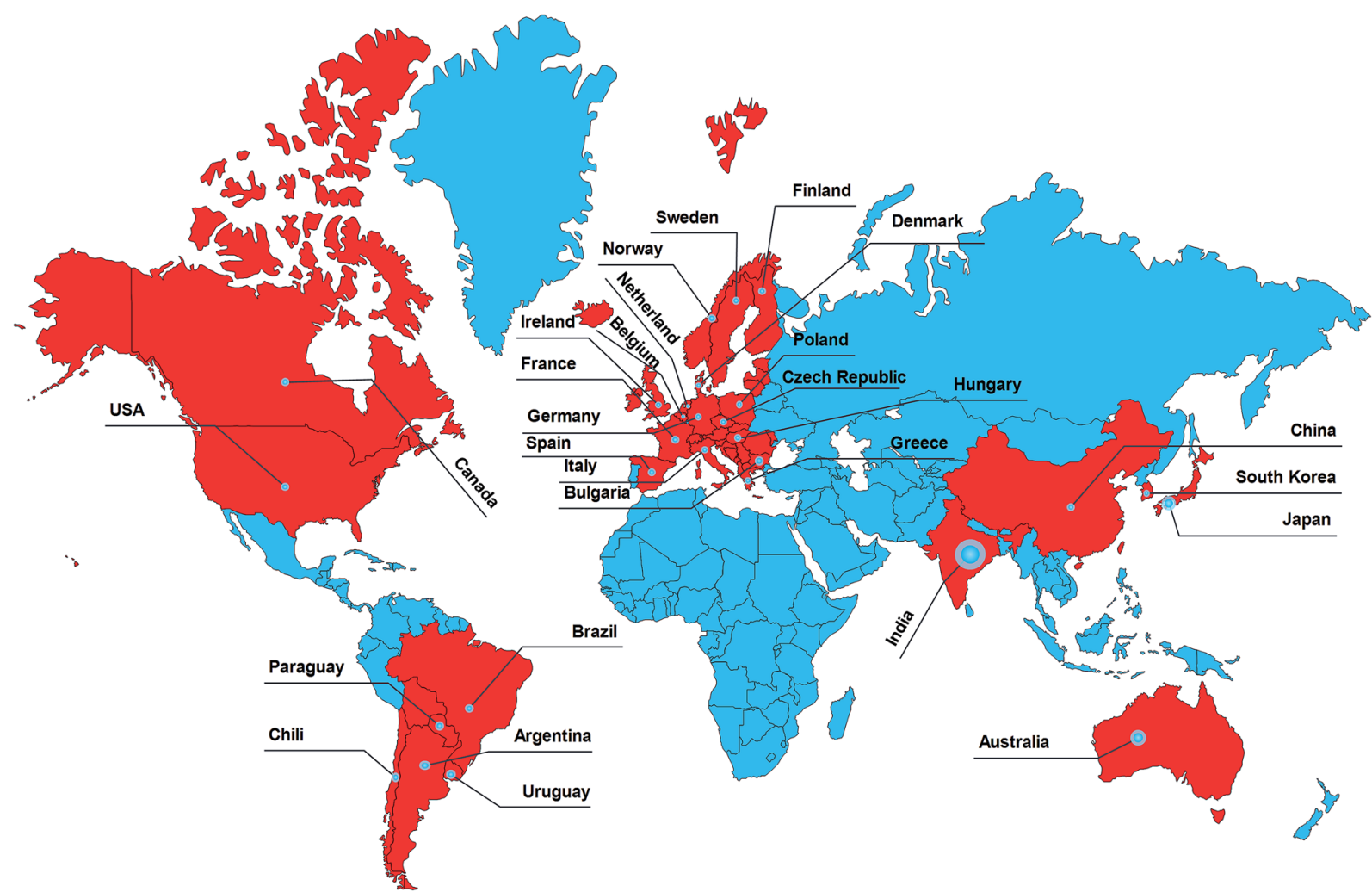

Fig. 1 Geographical distribution of Yersiniosis. Source: European Centre for Disease Prevention and Control, Yersiniosis, in ECDC, Annual epidemiological report for 2016, Stockholm, ECDC, 2018.

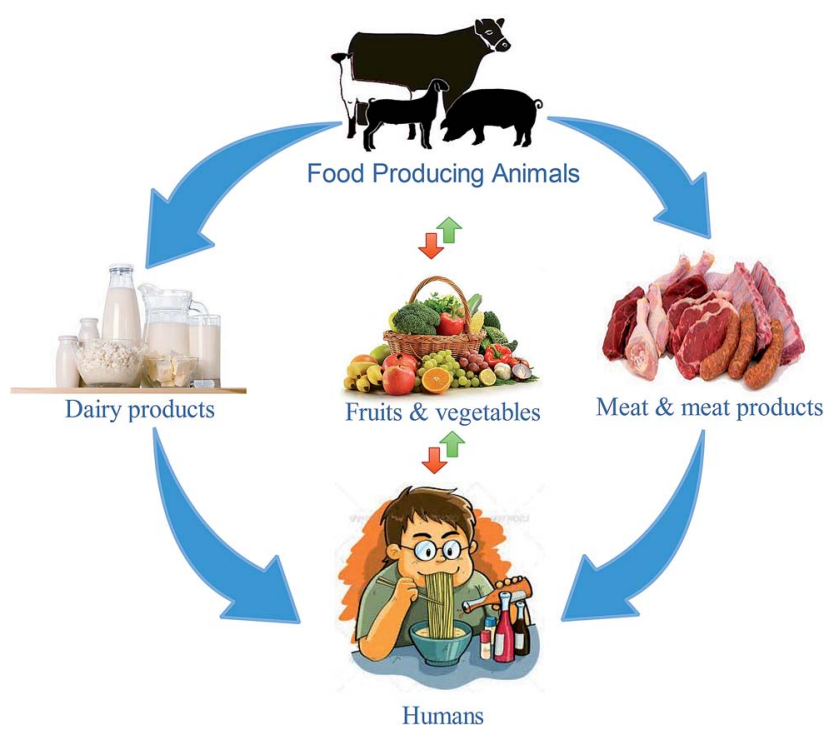

Fig. $2 Y$. enterocolitica transmission pathways to humans. Serotypes 2:09, 2:05, 3:03, 4:03, 5:O3 and 27 are transmitted directly or indirectly via animals or animal products; serotypes 2:09, 4:O3 and 5:O3 are specified for plant-based fresh produce.

sodium chloride solution and at $\mathrm{pH}$ up to 4.6 (ranging from 4 to 10). ${ }^{4}$ Thus, the growth ability in extreme conditions makes it a more alarming pathogen that can multiply in different conditions and therefore, it is considered as a severe threat to the consumers.
Table 1 Biochemical features of $Y$. enterocolitica

\begin{tabular}{ll}
\hline Characteristics & Y. enterocolitica \\
\hline Motion at $22{ }^{\circ} \mathrm{C}$ & + \\
Lipase at $22{ }^{\circ} \mathrm{C}$ & $\mathrm{v}$ \\
Ornithine decarboxylase & $\mathrm{v}$ \\
Urease & + \\
Citrate at $25^{\circ} \mathrm{C}$ & - \\
Voges-Proskauer test & $\mathrm{v}$ \\
Indole & $\mathrm{v}$ \\
Xylose & $\mathrm{v}$ \\
Trehalose & + \\
Sucrose & $\mathrm{v}$ \\
Rhamnose & - \\
Raffinose & $\mathrm{v}$
\end{tabular}

\section{Virulence factors and pathogenic mechanism}

Refrigerated contaminated food products, e.g., chocolate milk can only result in Yersiniosis, if they carry high doses $\left(10^{7}-10^{9}\right.$ $\mathrm{CFU} \mathrm{mL}^{-1}$ ) of $Y$. enterocolitica cells. The bacterial cell starts infecting the small intestine at terminal ileum and proximal colon, which are considered as the primary sites for infection. It is presumed that bacteria mainly use virulent gene products to colonize inside the intestine and with the rise in temperature $\left(37^{\circ} \mathrm{C}\right)$, they induce the expression of virulent gene $p Y V$ for the secretion of virulent factors. Later, these virulent factors (ail, 
Table 2 Y. enterocolitica key virulence factors and their genetics ${ }^{a}$

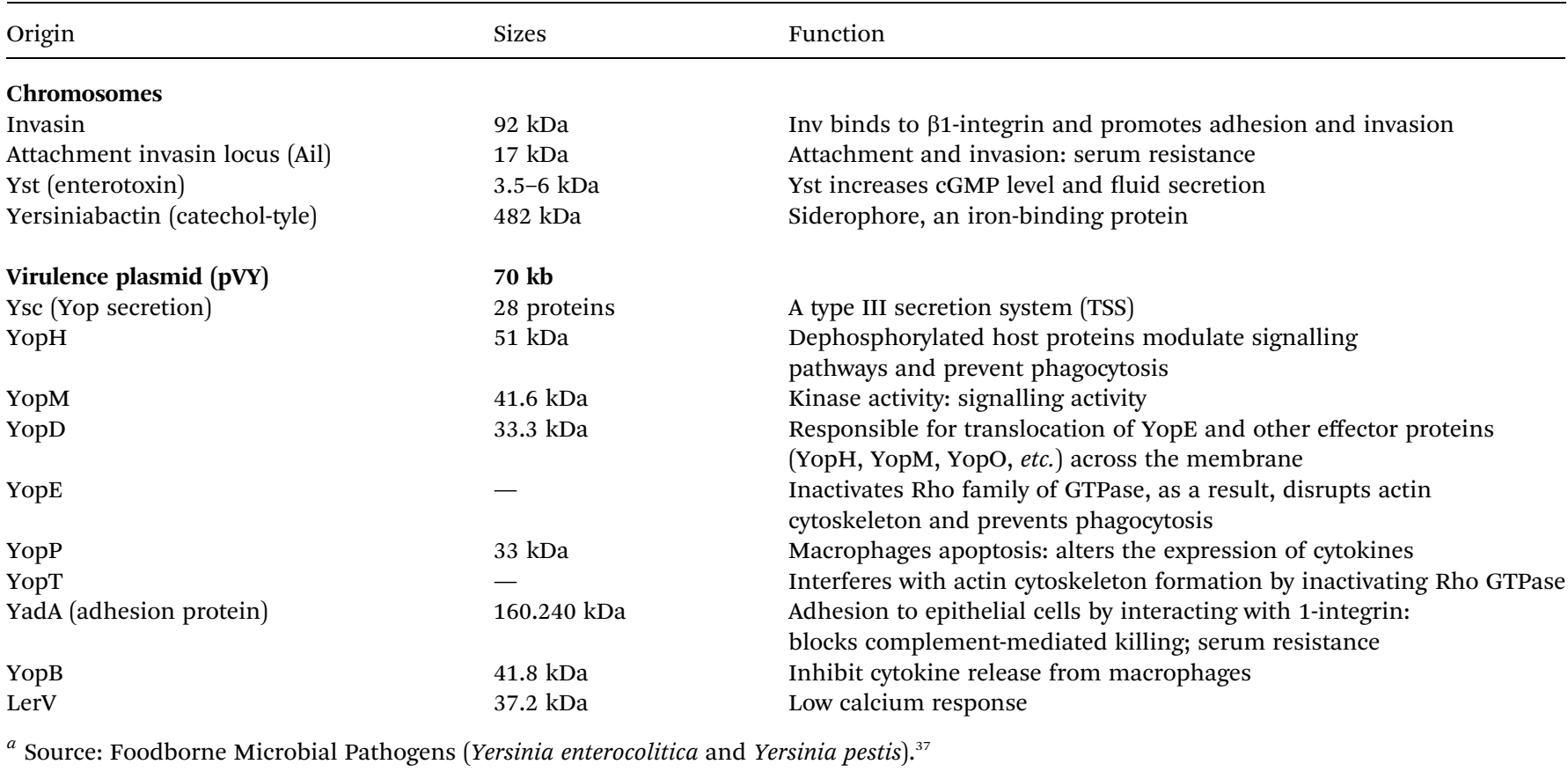

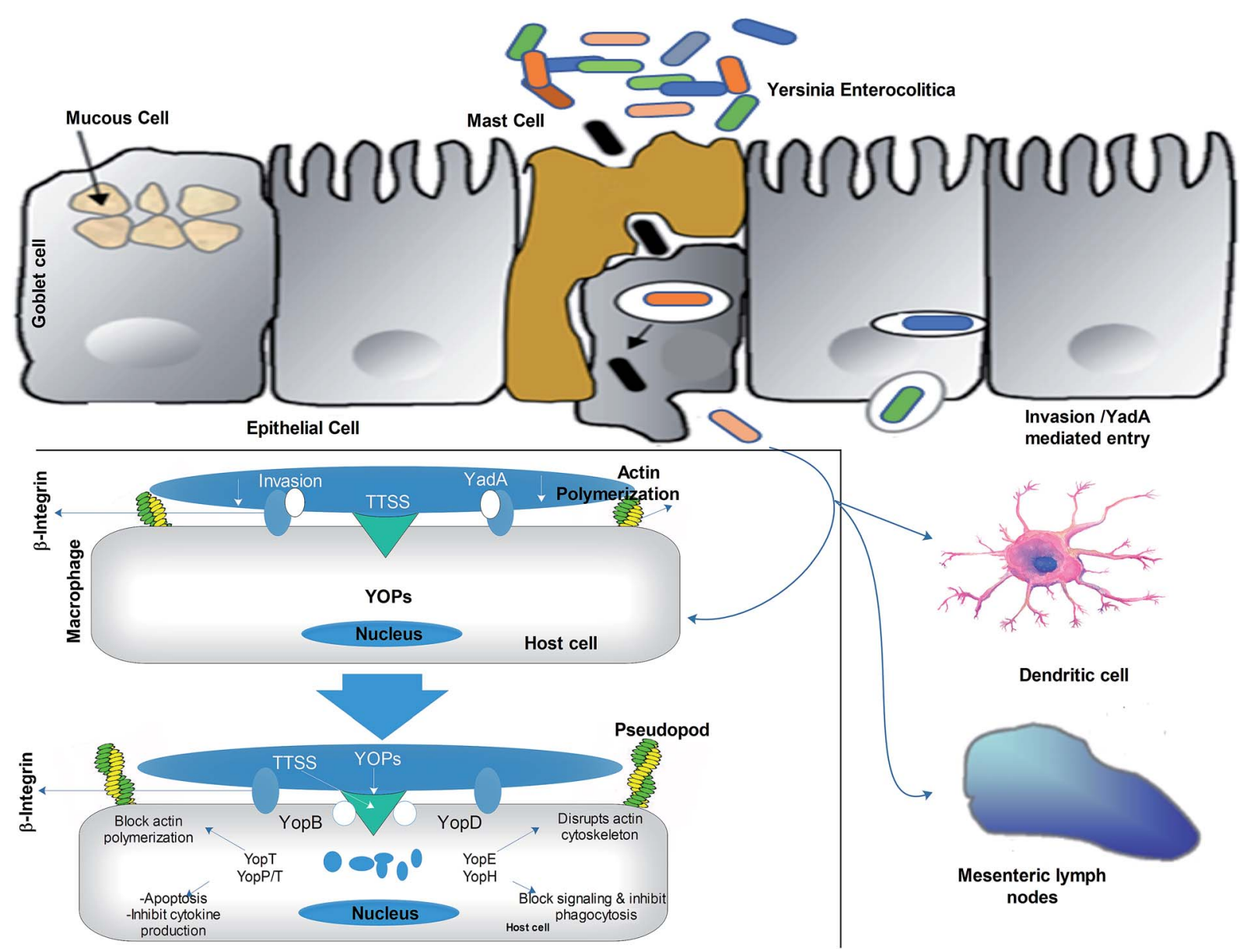

Fig. 3 Mechanism of the pathogenesis of $Y$. enterocolitica. The translocation of Yersinia is done via intestinal epithelial cells. Afterwards, they enter the basal layer through $\mathrm{M}$-cells and start invasion through the interaction with the $\beta 1$-integrin of the host cell. Later, they are transported to the lymph nodes and the liver by macrophages/dendritic cells, where they start delivering YOPs via type III system (TTSS) into the cytosol of the host cell. Y. enterocolitica safeguards itself from phagocytosis and macrophage apoptosis by retarding cytokine production. 
YadA) facilitate the binding of the bacterial cells to the mucous membrane and invade $\mathrm{M}$-cells. Invasive proteins interact with $\beta 1$-integrin receptors, which are abundantly located on M-cells. The virulent factor YadA supports the invasion by interacting with $\beta 1$-integrin receptors, collagen, fibronectin, and laminin. Then, the trapped bacteria are freed from the M-cells in the basal layer of the lamina propria and after multiplication in lymphatic follicles, they cause necrosis and abscesses in Peyer's patches. ${ }^{35}$

The key virulence factors are shown in Table 2. Besides, bacteria can reinvade the epithelial cells by using the $\beta 1$ integrin receptors positioned on their lateral basal surface. Bacteria spread from Peyer's patches to mesenteric lymph nodes, causing typical lymphadenitis. ${ }^{6,36}$ The bacterial cells also spread to the liver, spleen and lungs and propagate by protecting themselves from the phagocytosis of polymorphonuclear macrophages such as leukocytes and neutrophils. YOP is transmitted to the macrophages by TTSS, which blockades the process of phagocytosis and the oxidative outbreak of phagocytosis and induces apoptosis to interfere with cell signal transduction events, thus promoting the survival of the bacterium. Yersinia also inhibits inflammation by preventing macrophages and other immune cells from releasing pro-inflammatory cytokines (TNF-alpha, IFN-gamma, $I L-8)$. An overview of the pathogenesis mechanism is given in Fig. 3. In general, the TTSS system halts phagocytosis and suppresses the immune system, thus safeguarding the survival of bacteria in lymphoid tissues.

Furthermore, they cause abscesses in Peyer's patches by secreting enterotoxin Yst (to promote cell fluid secretion) to damage the epithelium; Yst- $a, Y s t-b$ and $Y s t-c$ activate membrane-bounded guanylate cyclase, resulting in the bigger deposition and activation of cyclic guanosine monophosphate (cgmp) in cells, followed by the stimulation of cGMP-dependent protein kinase. Enterotoxins terminate the biological reactions that inhibit sodium absorption and stimulation of chloride secretion. The resulting adverse effects can lead to septicemia, pneumonia, meningitis, and endocarditis, which can be lethal to immunocompromised hosts or individuals with underlying diseases. Y. enterocolitica infections can also develop nosocomial infections, arthritis, diarrhoea and sequelae in some patients. ${ }^{15,27,38}$ The understanding of the pathogenic mechanisms of this bacterium will help us develop strategies for the prevention and control of $Y$. enterocolitica.

\section{Isolation and detection}

The second part will present the available isolation and detection strategies for this pathogen. Several Yersiniosis cases reported in the past two decades have emphasized the necessity to study this pathogen and develop rapid, accurate, and economical detection methods. To prove the relationship between pathogens and epidemics, it is necessary to isolate and identify pathogens from suspicious food products. This is a challenging task because this bacterium grows slowly and dominates in the sample. ${ }^{7}$ Some phenotypic or molecular characteristics that are used to identify pathogenic strains rely on the presence of a virulent plasmid $(p Y V)$, while other characteristics are lost during the prolonged processes of culturing, isolation and detection. The in situ detection of $Y$. enterocolitica requires the separation of bacterial cells from the raw sample and the subsequent detection by different cultural methods. ${ }^{39}$ These methods are usually applied for qualitative analysis, but certain limitations like long latency, low sensitivity and lack of differentiation between pathogenic and non-pathogenic strains reduce the applicability of these methods. Thus, new formulations and standardization of these methods are still required for Y. enterocolitica.

\section{Cultural methods}

For decades, cultural methods have been used as the primary standard methods for pathogen detection. They can be applied in the detection of pathogens from natural sources like water, food and clinical samples. However, the high costs, timeconsumption, complexity, and low sensitivity of these methods hinder their applicability in the routine diagnosis of pathogens. Additionally, the concentration of $Y$. enterocolitica in the samples is always below the detectable limit, which requires additional pre-concentration steps to apply these culture methods for diagnosis.

In many studies, different selective media for preconcentration have been introduced to solve this problem. Selective media have been widely used for pre-enrichment with significant advantages; for example, an irgasan-ticarcillinpotassium chlorate (ITC) broth was used to increase the number of bacteria. Similarly, other formulated media like MacConkey agar, Hektoen enteric (HE) agar, xylose lysine deoxycholate (XLD), cefsulodin irgasan novobiocin (CIN) agar and virulent $Y$. enterocolitica (VYE) agar have been used for the isolation of $Y$. enterocolitica. CIN agar and esculin-modified CIN agar are used as differential media, on which this bacterium produces red "bull's eye" colonies, as shown in Fig. 4, whereas other Yersinia spp. produce dark colonies. ${ }^{40}$ Phosphate buffer saline (PBS) and trypsin soybean soup (TSB) have been reported as the best media for the pre-enrichment of the samples of $Y$. enterocolitica. . $^{\mathbf{1 7 4 1 , 4 2}}$

However, in the culturing methods, the prolonged incubation time leads to the growth of other psychrophilic bacteria, which limits their further application. This problem was overcome by employing an alkali treatment to enrich the culture in $Y$. enterocolitica and reduce the competitive background microflora since $Y$. enterocolitica can multiply in an alkaline environment as compared to other Gram-negative bacteria. ${ }^{43}$ In another study, selective media containing discriminatory antimicrobials were formulated to concentrate the bacterial cells at high temperatures like the Modified Rappaport Broth (MRB) applied for the rapid recovery of serotype O:3 at $25{ }^{\circ} \mathrm{C}$ for $2-4$ days and for the quick recovery of bacterial cells, the selection of media depends on sample types, Like selenite medium was used for meat samples, irgasan-ticarcillin-chlorate (ITC) broth for isolation of serotype O:3, improved TSB for recovery of $Y$. enterocolitica from ready-to-eat food and pork samples. LuriaBertani bile salt irgasan (LB-BSI) was also supplemented with 


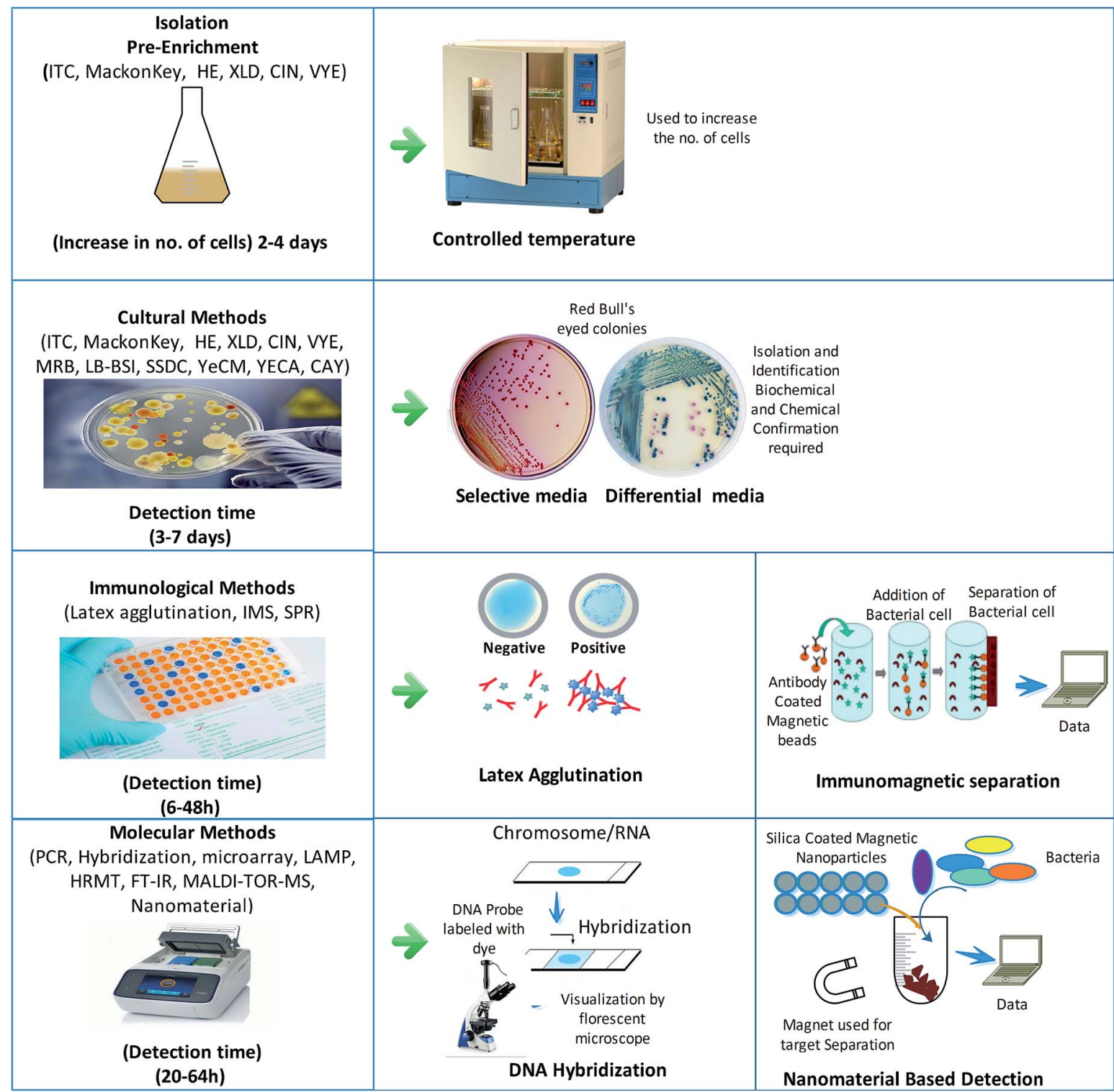

Fig. 4 Schematic summary of available culturing and detection methods.

cefsulodin and novobiocin for the recovery of $Y$. enterocolitica at $12{ }^{\circ} \mathrm{C} .{ }^{44}$

The above media are used for the pre-concentration of $Y$. enterocolitica and other selective media were reported for its isolation, including MacConkey agar, Salmonella Shigella deoxycholate calcium (SSDC) agar and Cefsulodin-IrgasanNovobiocin (CIN) agar. Although three different chromogenic media, namely, Y. enterocolitica chromogenic medium (YeCM), $Y$. enterocolitica agar-selective chromogenic medium (YECA) and CHROMAgar (CAY) have also been developed for use in diagnostic and clinical laboratories, it was observed that CIN Agar modified with L-arginine, ferric ammonium citrate, sodium thiosulfate and DL-phenylalanine had better identification ability for $Y$. enterocolitica over other bacteria in food samples. ${ }^{7,40,45-47}$ Importantly, the ISO method for food samples (ISO 10273:2003) also includes the use of the PBS broth, ITC broth for pre-concentration, and CIN for plating. ${ }^{48}$ Similarly, other developed methods, such as NMKL method No-117, NCFA, BAM-U.S. FDA, indicated the cold enrichment of $Y$. enterocolitica on PSB and MRB. These expensive and labourintensive laboratory preparations persist as a challenge for the routine screening of $Y$. enterocolitica in the food industry. ${ }^{49}$ Therefore, further improvements are needed in the traditional culture methods for the isolation and identification of $Y$. enterocolitica.

\section{Immunological methods}

The recent advancements in pathogen detection have improved accuracy and time. In this context, a lot of immunoassays have been reported for the quick recognition of microorganisms without culturing. The simplest method developed for the detection of $Y$. enterocolitica serotype O:3/O:9 and serotypes O:3, O:6 or $0: 9$ involves the use of latex agglutination assays, in 
which specified antibody-coated latex beads are agglutinated with antigens to form visible precipitates. ${ }^{50}$ The immunomagnetic separation (IMS) strategy reduces the detection time by 24 hours and eliminates the pre-enrichment step. In this method, magnetic beads covered with target-specific antibodies are used to sort out the pathogen from a cocktail of microorganisms, as shown in Fig. 4. In one study, Y. enterocolitica could be sorted out by the IMS method and confirmed by nested PCR using the specified primers for the $Y$. enterocolitica adhesion gene (yadA), achieving $10^{4}$ to $10^{7} \mathrm{CFU} \mathrm{mL} \mathrm{m}^{-1}$ LOD (limit of detection) for clinical and environmental samples. ${ }^{51}$ This method was more specific and could differentiate pathogenic and non-pathogenic strains without any cross-reactivity. However, this method was applied to detect pathogenic strains lacking the $p Y V$ virulent gene. A new surface plasmon resonance (SPR)-based immunosensor constructed for the quick recognition of $Y$. enterocolitica with LOD of $10^{2}-10^{7} \mathrm{CFU}$
$\mathrm{mL}^{-1}$ was developed, where the antibody-antigen reaction was used for detection by immobilizing the antibodies on the SPR surface. $^{52}$ A sandwich-type multiplex chemiluminescence immunoassay was established by using peroxidase-labelled monoclonal antibodies; the peroxidase activity of bound polyclonal antibodies was measured by an enhanced luminol-based cocktail using a low-light charge-based coupled imaging device. This method is considered to be rapid and accurate for detection as compared to the conventional culturing methods. It can detect up to $10^{4}-10^{5} \mathrm{CFU} \mathrm{mL}^{-1}$ bacterial cells in samples with high recovery values of around $90-120 \% .^{53}$ Direct antigen detection provides rapid and specific identification results; however, the specificity of these methods is limited by the quality of the antibodies. These analyses usually require many antigens in the sample, which involves concentration steps before analysis, thus increasing the detection time. Also, these

Table 3 Recently developed detection methods for $Y$. enterocolitica

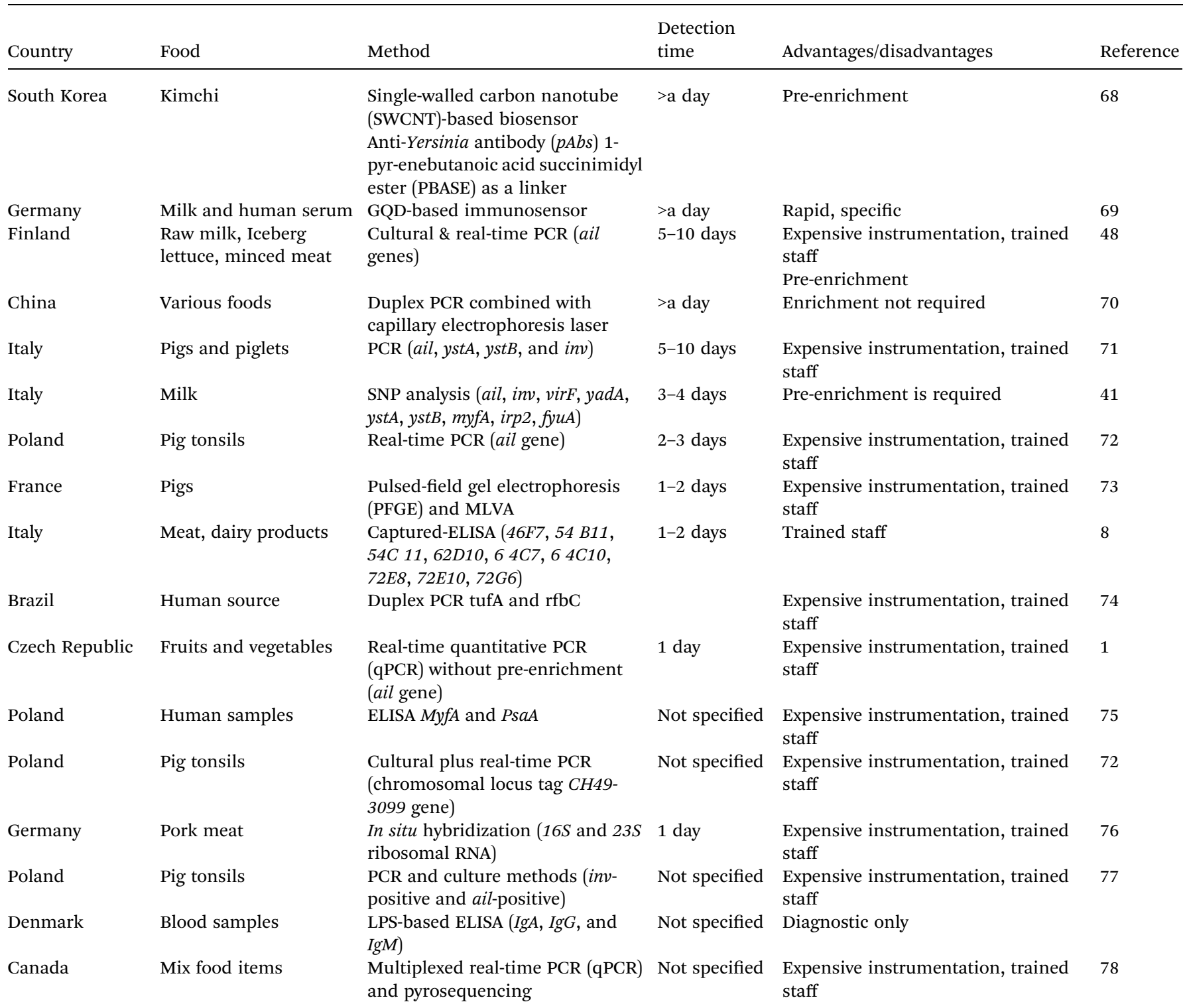


immunization methods may be affected by in vitro test conditions and may lead to false detection.

\section{Molecular techniques}

The molecular technology has also been considered as a promising tool for the quick detection of pathogens by limiting the problems of the culture technology. The culture technology is time-consuming and laborious and the identification results of pathogenic and non-pathogenic bacteria are also unreliable. ${ }^{29}$ Genomic targets are used in molecular techniques for the specific detection of pathogens in food samples. Standard methods include colony hybridization, PCR, isothermal amplification and microarray technologies. Generally, the polymerase chain reaction (PCR) is considered the most suitable technique for the detection of $Y$. enterocolitica. In this review, we have summarized the latest molecular and immunological detection methods (Table 3).

\section{Molecular typing methods}

Pathogens always cause severe illnesses, but their detection in food samples still remains a challenge. In this regard, nucleic acid-based detection analyses are very prominent. The revolution in the molecular technology has enabled scientists to develop a series of fast, economical, and accurate molecular techniques. Different examples include population hybridization, polymerase chain reaction, nested polymerase chain reaction, real-time polymerase chain reaction, microarray technology, and loop-mediated isothermal amplification (LAMP) technique. ${ }^{54}$ Commonly applied methods for the detection of $Y$. enterocolitica include the probing of target virulence-related DNA sequences, such as ail (attachment and invasion locus), inv (invasin), or yst (Yersinia stable toxin) genes. ${ }^{55}$ Besides the great advantage of the higher sensitivity of molecular methods over traditional cultural methods, there are still certain limitations, like the competing microflora, which tend to decrease the hybridization efficiency.

In the field of microbiological diagnostics, PCR-based assays have gained great popularity due to their speed, costeffectiveness, and the comfort of automation. In most cases, the polymerase chain reaction (PCR) uses chromosomal virulence genes, such as ail, inv, and yst, as the targets or main targets of $Y$. enterocolitica detection. The limitations of preenrichment, pre-PCR sample preparation, selection of the right single gene or a mixture of genes, and analysis of PCR products result in the establishment of new types of PCR assays. The European Committee for Standardization's (CEN) recommendations regarding the PCR-based detection protocols of foodborne pathogens have led to the development of real-time PCR-based methods. Real-time PCR meets the criteria of CEN due to its high detection probability, good accuracy, simplicity, little or reduced residue contamination and easy-to-access protocols. Recently, the real-time polymerase chain reaction (PCR) has been applied to detect $Y$. enterocolitica in food samples. These methods use virulence-related genes, especially ail genes. Though these PCR-based methods meet the criteria of CEN, some issues arise like the fact that common molecular markers (ail, myf, yst) on the pathogenic and non-pathogenic biovars of $Y$. enterocolitica make it hard to differentiate viable and non-viable cells, while the presence of inhibitory substances in food samples limits their application. One way to resolve these issues is by introducing pre-enrichment steps before PCR. The use of negative controls limits crosscontamination for post-PCR measures. Moreover, PCR can be multiplexed to allow multiple detections of targets to ensure high specificity. Several multiplex PCR methods have been developed to amplify more than two virulence genes for the specific detection of Y. enterocolitica in food samples. ${ }^{56}$ Weagant and co-workers developed multiplex PCR using rfbC (O-antigen encoding gene), inv, ail, and virF gene primers for the specific detection of $Y$. enterocolitica serotype O:3. ${ }^{49}$ Recently, a new PCRbased approach was developed for the identification and serotyping of $Y$. enterocolitica, where the first multiplex PCR identified species and subspecies levels using 16SrRNA, inv, ail, and $y s t B$, followed by nested PCR for differentiating the serotypes associated with human infections using serotype-specific primers, $r f b C / w b b U / w b c A / w z t .{ }^{57}$ As most of these are based on "Taqman and SYBR green" methods, this gene-based serotyping scheme can be applied for the reliable identification of toxic $Y$. enterocolitica. ${ }^{58,59}$

The high-resolution melting technology (HRMT) is one of the recent advancements in molecular biology for the detection of bacteria by single nucleotide polymorphisms (SNPs), hypervariable repeats and mutations in PCR amplicons. The changes in nucleotides at specific sites can be monitored in closed-tube analysis after PCR and then, the fluorescence of the PCR products labelled with specific dyes can be detected to observe the transformation of unfused and melted DNA. Although, this method reduces the time and minimizes the risk of crosscontamination, it requires sequence variants with desired melting points and labelled primers. ${ }^{60}$

Although, PCR techniques have many benefits over traditional culture methods, they still require highly trained labour, expensive instruments (electrophoresis and thermal cycler machines) and complicated sample pre-treatments, which make their application difficult for real samples. Lately, a new technique of isothermal amplification has been introduced, which simplifies the amplification of targeted nucleic acids at the laboratory level with inexpensive instrumentation, requiring only a water bath at a constant temperature. For example, highly specific, visualized and fast methods, such as LAMP (loopmediated isothermal amplification), use temperatures of 60$65^{\circ} \mathrm{C}$ and are based on DNA synthesis by spin-loop substitution employing DNA polymerase and two sets of primers: external primers generate a stem-loop DNA for a LAMP cycle, and internal primers are used for chain shifting during DNA amplification. The LAMP-amplified products can be detected by the naked eye, fluorescence and turbidity measurements. A turbidimeter is used to assess the turbidity of solutions as it can measure the change in turbidity due to magnesium pyrophosphate complex formation or fluorescence of amplicons upon the addition of fluorescent reagents, such as SYBR Green 1 or 
fluorescent metals. $Y$. enterocolitica was detected in minced pork and milk samples by using gyrB, phoP, and outL genes as the targets by the LAMP method. ${ }^{61,62}$ Zhang and co-workers employed another type of CPA, in which the testing primers were modified with biotin and FITC (fluorescein isothiocyanate) and combined with an immunoblotting assay of nucleic acid lateral flow strips. Noticeable results of detection were achieved by dipping the strips in an anti-biotin solution; two red lines appeared for positive results, whereas one red line was observed in case of false outcomes. This method is 100 times more sensitive as compared to PCR, with the detection limit of 10-100 CFU g ${ }^{-1} \cdot{ }^{63,64}$

Besides the development of these methods, the emergence of microarray assays brings more advancements in the detection of pathogens. In this technique, pathogens are immobilized and later detected by implementing different strategies. $Y$. enterocolitica can be detected in various samples by developing microchips with the combination of the PCR amplification of multiple genes (ail, virF, yst, and blaA) and random DNA fragments. Recently, a silicon-based optical thin-film biosensor chip was developed for the sensitive detection of 11 foodborne pathogens, including $Y$. enterocolitica. Fourier transform infrared spectroscopy (FT-IR) and matrix-assisted laser desorption/ionization time-of-flight mass spectrometry (MALDI-TOF-MS) ${ }^{65}$ are new methods developed in recent years, which can be used to identify the species and subspecies of $Y$. enterocolitica. In another study, Y. Enterocolitica was detected in samples due to its ability of conjugation with deferoxamine by the cell surface siderophore receptor of bacterial cells. In this method, deferoxamine-modified bovine serum albumin was fixed on gold plates and upon introduction of bacterial cells, deferoxamine-Fe composites were formed, which were rapidly detected by dark field microscopy analysis with a detection limit of $10^{3} \mathrm{CFU} \mathrm{mL} \mathrm{m}^{-1}$. $^{6}$

Furthermore, the same phenomenon was used in another study, where silica-coated magnetic nanoparticles functionalized with feroxamine (MNP@SiO $\left.\mathrm{MNH}_{2} @ \mathrm{Fa}\right)$ were fabricated; the bacterial cells were successfully captured and detected in the samples. The main problem associated with this method involves the blockage material for non-specific binding, the development of new blockage materials, and validity or updating of the method. ${ }^{67} \mathrm{~A}$ high speed, ease of use and highthroughput analysis make these techniques superior to other identification methods, which can be used to detect Yersinia spp. However, these methods need to be further modified to reduce their high costs and long sample preparation requirements for routine testing.

\section{Prevention and control}

Y. enterocolitica is a psychrotroph and therefore, refrigeration cannot be used to control its growth. Proper sanitation at all stages of handling and processing foods and appropriate heat treatments are essential to monitor the occurrence of foodborne yersiniosis. The consumption of raw milk or meat cooked at low temperatures should be avoided. $Y$. enterocolitica, being susceptible to heat and pasteurization, can be easily destroyed by ionizing radiation, UV-radiation, and other food preservation procedures. Recently, a pulsed light-based reduction method was introduced for pork meat: the product was kept in a benchtop sterilization system (SteriPulse-XL 3000, Model RS3000C, Xenon Corporation, Wilmington, Massachusetts, USA) and analysed for microbial analysis. The results showed that the pulsed light treatment $(20-1100 \mathrm{~nm})$ significantly reduced the number of bacterial cells through the formation of pyrimidine dimers, primarily thymine dimers, and the destruction of these cells due to the photochemical effect, which inhibited cell replication and led to clonogenic death. ${ }^{79}$ In another study, virulent bacteriophages Podoviridae ( $\mathrm{fHe}$-Yen3-01) and Myoviridae (fHe-Yen9-01, fHe-Yen9-02 and fHe-Yen9-03) were applied to raw pork samples to control $Y$. enterocolitica contamination. The results showed that $\mathrm{fHe}$-Yen9-01 was the most effective bacteriophage with the maximum host range. ${ }^{80} Y$. enterocolitica biotype 4 has the ability of biofilm formation in meat processing units; sodium hypochlorite and quaternary ammonium compounds (QAC) were found to be the most active compounds to avoid these biofilm formations. ${ }^{81}$

Yersinia produces two types of $\beta$-lactamases (enzymes that hydrolyse the $\beta$-lactam ring of $\beta$-lactam antibiotics) and is thus resistant to the penicillin group of antibiotics. Due to $\beta$ lactamase activity, this pathogen shows natural resistance to penicillin but is considered sensitive to newer antimicrobial $\beta$-lactam antibiotics such as ceftriaxone, ceftazidime, and moxalactam. Moreover, the $Y$. enterocolitica strains are the most susceptible to aminoglycosides, extended-spectrum cephalosporins, trimethoprim-sulfamethoxazole, tetracyclines, and fluoroquinolones..$^{\mathbf{4 , 1 9 , 7 1}} \mathrm{Y}$. enterocolitica is equally sensitive to imipenem and aztreonam antibiotics. Broadspectrum cephalosporins are also effective against extraintestinal infections. Resistance to fluoroquinolones occurs sporadically either due to a mutation in the gyrA gene or efflux mechanisms. Multi-resistant strains have been reported among pig strains belonging to bioserotype 4:O3. ${ }^{82}$ The inactivation of multidrug-resistant $Y$. enterocolitica on a stainless steel surface by cold atmospheric pressure plasma (CAP) treatment with peak-to-peak voltage of $10 \mathrm{kV}$ and sinusoidal waveform of $2 \mathrm{kHz}$ was also reported, where the direct antigen detection provided rapid and specific identification results. However, the specificity of these methods is limited due to the shelflife, batch to batch alteration and quality of antibodies. Propidium iodide and SYTO 9 were also used as staining and cell destruction agents according to some reports. The significant durationdependent reduction ranged from $1.68 \pm 0.17$ to $2.80 \pm$ $0.17 \log .{ }^{83}$ Still, more investigations and the development of new strategies are required for the control and prevention of Y. enterocolitica.

\section{Concluding remarks}

Yersiniosis is a gastrointestinal ailment triggered by $Y$. enterocolitica. At present, many cultural, immunological, and molecular techniques are being used for the detection of this pathogen. The use of CIC and SSDC agar is dominant for its 
isolation and identification, but carrying out these methods is cumbersome, lengthy and unreliable and needs biochemical confirmation. Therefore, the detection of $Y$. enterocolitica in food was improved by introducing serological and molecular methods such as IMS, bacterial hybridization, PCR, microarray assays, and LAMP. The low incidence of $Y$. enterocolitica in food is related to the insensitivity of the current detection methods. In the future, approaches based on chromogenic/fluorogenic media, immuno-PCR, biosensors, flow cytometry, nucleic acid sequencing and aptamerbased detection can be optimized and developed for more accurate and routine diagnostics of $Y$. enterocolitica. These will serve as powerful tools for authorities to accurately estimate and reduce the incidence of Yersiniosis.

\section{Abbreviations}

$\begin{array}{ll}\text { SNPS } & \text { Single nucleotide polymorphism } \\ \text { CPA } & \text { Cross priming amplification } \\ \text { LAMP } & \text { Loop-mediated isothermal amplification } \\ \text { CDC } & \text { Centre for disease control and prevention } \\ \text { QAC } & \text { Quaternary ammonium compound } \\ \text { IMS } & \text { Immunomagnetic separation }\end{array}$

\section{Conflicts of interest}

There are no conflicts to declare.

\section{Acknowledgements}

We pay special thanks to the Chinese Government Scholarship Council for their financial support and Jiangnan University, Wuxi, Jiangsu, China, for providing the platform for research, data collection and compiling the article.

\section{References}

1 V. Verbikova, G. Borilova, V. Babak and M. Moravkova, Food Control, 2018, 85, 161-167.

2 S. Ahmad, S. Raza, Qurat-ul-Ain, R. Uddin, T. Rungrotmongkol and S. S. Azam, J. Mol. Liq., 2018, 265, 372-389.

3 A. Golubov, J. Heesemann and A. Rakin, FEMS Immunol. Med. Microbiol., 2003, 38, 107-111.

$4 \mathrm{M}$. Fredriksson-Ahomaa, Yersinia enterocolitica, in Foodborne Diseases, Academic Press, 3rd edn, 2017, pp. 223-233.

5 E. J. Bottone, Yersinia enterocolitica, Academic Press, 2018.

6 R. Tuompo, T. Hannu, E. Huovinen, L. Sihvonen, A. Siitonen and M. Leirisalo-Repo, Rheumatol. Int., 2017, 37, 1863-1869.

7 S. Petsios, M. Fredriksson-Ahomaa, H. Sakkas and C. Papadopoulou, Int. J. Food Microbiol., 2016, 237, 55-72.

8 M. Luciani, M. Schirone, O. Portanti, P. Visciano, G. Armillotta, R. Tofalo, G. Suzzi, L. Sonsini and T. Di Febo, Food Microbiol., 2018, 73, 85-92.
9 J. Liang, R. Duan, S. Xia, Q. Hao, J. Yang, Y. Xiao, H. Qiu, G. Shi, S. Wang and W. Gu, Vet. Microbiol., 2015, 178, 125131.

10 L. A. Rusak, R. M. Junqueira, E. Hofer, D. C. Vallim and M. D. Asensi, Braz. J. Infect. Dis., 2017, 21, 550-553.

11 D. W. Challener, E. M. Tan and J. C. O'Horo, J. Med. Cases, 2017, 8, 359-360.

12 Q. Ye, Q. Wu, H. Hu, J. Zhang and H. Huang, FEMS Microbiol. Lett., 2015, 362, fnv197.

13 Š. Bursová, L. Necidová, D. Haruštiaková and B. Janštová, Food Control, 2017, 73, 1415-1419.

14 K. Söderqvist, S. T. Lambertz, I. Vågsholm and S. Boqvist, J. Food Prot., 2016, 79, 978-985.

15 I. Sugrue, C. Tobin, R. P. Ross, C. Stanton and C. Hill, in Raw Milk, Elsevier, 2019, pp. 259-272.

16 S. Bonardi, A. Paris, L. Bassi, F. Salmi, C. Bacci, E. Riboldi, E. Boni, M. D'incau, S. Tagliabue and F. Brindani, J. Food Prot., 2010, 73, 1785-1792.

17 B. T. F. Martins, C. V. Botelho, D. A. L. Silva, F. G. P. A. Lanna, J. L. Grossi, M. E. M. Campos-Galvão, R. S. Yamatogi, J. P. Falcão, L. d. S. Bersot and L. A. Nero, Int. J. Food Microbiol., 2018, 276, 5-9.

18 M. Ikeda, N. Yamaguchi, K. Tani and M. Nasu, J. Health Sci., 2006, 52, 36-42.

19 Z. Peng, M. Zou, M. Li, D. Liu, W. Guan, Q. Hao, J. Xu, S. Zhang, H. Jing, Y. Li, X. Liu, D. Yu, S. Yan, W. Wang and F. Li, Food Control, 2018, 93, 121-128.

20 Food and Drug Administration, Gram-positive bacteria, in Bad bug book, foodborne pathogenic microorganisms and natural toxins, ed. K. Lampel, S. Al-Khaldi and S. Cahill, Silver Spring, Center for Food Safety and Applied Nutrition of the Food and Drug Administration (FDA), US Department of Health and Human Services, 2nd edn, 2012, https://www.fda.gov/files/food/published/Bad-Bug-Book2nd-Edition-\%28PDF\%29.pdf.

21 S. Keisam, N. Tuikhar, G. Ahmed and K. Jeyaram, Int. J. Food Microbiol., 2019, 296, 21-30.

22 D. M. Rodio, A. Bressan, C. Ambrosi, D. Scribano, R. Tolli, W. Mansour, F. Speziale, G. Antonelli, M. Trancassini and V. Pietropaolo, Front. Med., 2018, 5, 156.

23 E. MacDonald, M. Einöder-Moreno, K. Borgen, L. T. Brandal, L. Diab, Ø. Fossli, B. G. Herrador, A. A. Hassan, G. S. Johannessen and E. J. Johansen, Eurosurveillance, 2016, 21(34).

24 K. Söderqvist, S. T. Lambertz, I. Vågsholm, L.-L. Fernström, B. Alsanius, L. Mogren and S. Boqvist, J. Food Prot., 2017, 80, 204-212.

25 R. Duan, J. Liang, J. Zhang, Y. Chen, J. Wang, J. Tong, B. Guo, W. Hu, M. Wang and J. Zhao, Emerging Infect. Dis., 2017, 23, 1502.

26 D. I. Johnson, in Bacterial Pathogens and Their Virulence Factors, Springer, 2018, pp. 407-421.

27 C. M. G. de Almeida, F. C. Maluf, F. C. Maluf, V. P. Lanzoni, D. R. Kiss and M. G. de Almeida, Journal of Coloproctology, 2018, 38, 343-345.

28 K. J. Stanger, H. McGregor, M. Marenda, J. M. Morton and J. W. A. Larsen, Prev. Vet. Med., 2018, 153, 30-41. 
29 V. Gupta, P. Gulati, N. Bhagat, M. S. Dhar and J. S. Virdi, Eur. J. Clin. Microbiol. Infect. Dis., 2015, 34, 641-650.

30 M. Tavassoli, A. Afshari, D. Draganescu and A. Letitia, Farmacia, 2018, 66, 399-407.

31 A. M. Jakobsen, M. I. Bahl, T. Buschhardt, T. B. Hansen, W. A. Al-Soud, A. D. Brejnrod, S. J. Sørensen, T. Nesbakken and S. Aabo, Int. J. Food Microbiol., 2019, 295, 8-18.

32 E. J. Bottone, in Yersinia Enterocolitica, CRC Press, 2018, pp. 11-18.

33 A. Bancerz-Kisiel, M. Gral, M. Odyniec and W. Szweda, Comp. Immunol. Microbiol. Infect. Dis., 2019, 63, 131-135.

34 B. Asadishad, S. Ghoshal and N. Tufenkji, Environ. Sci. Technol., 2013, 47, 14169-14177.

35 A. K. Bhunia, in Foodborne Microbial Pathogens, Springer, 2018, pp. 301-313.

36 P. B. Carter, in Yersinia enterocolitica, CRC Press, 2018, pp. 83-92.

37 A. K. Bhunia, Yersinia enterocolitica and Yersinia pestis, in Foodborne Microbial Pathogens: Mechanisms and Pathogenesis, Springer New York, New York, NY, 2008, pp. 227-240.

38 E. Bohn, M. Sonnabend, K. Klein and I. B. Autenrieth, Int. J. Med. Microbiol., 2019, 309, 344-350.

39 I. Van Damme, L. De Zutter, L. Jacxsens and M. J. Nauta, Food Microbiol., 2017, 64, 83-95.

40 L. K. Tan, P. T. Ooi and K. L. Thong, Food Control, 2014, 35, 94-100.

41 S. Bonardi, A. S. Le Guern, C. Savin, G. Pupillo, L. Bolzoni, M. Cavalca and S. Pongolini, Int. Dairy J., 2018, 84, 46-53.

42 P. Van Lint, E. De Witte, H. De Henau, A. De Muynck, L. Verstraeten, B. Van Herendael and S. Weekx, Eur. J. Clin. Microbiol. Infect. Dis., 2015, 34, 535-542.

43 E. de Boer, in Handbook of Culture Media for Food and Water Microbiology (3), The Royal Society of Chemistry, 2012, pp. 298-320.

44 J. A. Hudson, N. J. King, A. J. Cornelius, T. Bigwood, K. Thom and S. Monson, Int. J. Food Microbiol., 2008, 123, 25-31.

45 M. Denis, E. Houard, A. Labbé, M. Fondrevez and G. Salvat, J. Pathog., 2011, 2011, 296275.

46 R. Laukkanen, M. Hakkinen, J. Lundén, M. FredrikssonAhomaa, T. Johansson and H. Korkeala, J. Appl. Microbiol., 2010, 108, 956-964.

47 N. Renaud, L. Lecci, R. J. Courcol, M. Simonet and O. Gaillot, J. Clin. Microbiol., 2013, 51, 1184-1187.

48 S. Hallanvuo, M. Herranen, A. Jaakkonen, M. Nummela, J. Ranta, N. Botteldoorn, L. De Zutter, M. FredrikssonAhomaa, S. Hertwig, G. S. Johannessen, M. Ludewig, U. Messelhäußer, P. Sigvart-Mattila, S. Thisted-Lambertz, T. Thure and E. Vatunen, Int. J. Food Microbiol., 2019, 288, 66-74.

49 S. D. Weagant, J. Microbiol. Methods, 2008, 72, 185-190.

50 R. V Lachica and D. L. Zink, J. Clin. Microbiol., 1984, 19, 660663.

51 C. S. M. Lucero Estrada, L. del C. Velázquez, G. I. Favier, M. S. Di Genaro and M. E. Escudero, Food Microbiol., 2012, 30, 157-163.
52 B.-K. Oh, W. Lee, B. S. Chun, Y. M. Bae, W. H. Lee and J.-W. Choi, Colloids Surf., A, 2005, 257-258, 369-374.

53 M. Magliulo, P. Simoni, M. Guardigli, E. Michelini, M. Luciani, R. Lelli and A. Roda, J. Agric. Food Chem., 2007, 55, 4933-4939.

54 S. Hanifian and S. Khani, Int. J. Food Microbiol., 2012, 155, 89-92.

55 A. Bancerz-Kisiel, M. Pieczywek, P. Łada and W. Szweda, Genes, 2018, 9, 235.

56 S. Thisted Lambertz and M.-L. Danielsson-Tham, Appl. Environ. Microbiol., 2005, 71, 3674-3681.

57 D. Garzetti, R. Susen, A. Fruth, E. Tietze, J. Heesemann and A. Rakin, Int. J. Med. Microbiol., 2014, 304, 275-283.

58 H. Najdenski, M. Heyndrickx, L. Herman, H. Werbrouck and E. Van Coillie, Vet. Microbiol., 2012, 160, 428-434.

59 M. Fredriksson-Ahomaa, S. Joutsen and R. LaukkanenNinios, Current Clinical Microbiology Reports, 2018, 5, 135142.

60 R. A. Souza, M. R. Frazão, A. M. P. Almeida and J. P. Falcão, J. Microbiol. Methods, 2015, 115, 6-12.

61 H. Gao, Z. Lei, J. Jia, S. Wang, Y. Chen, M. Sun and C. Liang, J. Microbiol. Methods, 2009, 77, 198-201.

62 Y. Li, M. Jiang, W. Liu, L. Zhang, S. Zhang, X. Zhao, R. Xiang and Y. Liu, Mol. Cell. Probes, 2010, 24, 68-71.

63 X. Huang, C. Zhai, Q. You and H. Chen, Anal. Bioanal. Chem., 2014, 406, 4243-4249.

64 H. Zhang, S. Feng, Y. Zhao, S. Wang and X. Lu, Int. J. Food Microbiol., 2015, 214, 77-82.

65 P. Lasch, M. Drevinek, H. Nattermann, R. Grunow, M. Stämmler, R. Dieckmann, T. Schwecke and D. Naumann, Anal. Chem., 2010, 82, 8464-8475.

66 Y. Kim, D. P. Lyvers, A. Wei, R. G. Reifenberger and P. S. Low, Lab Chip, 2012, 12, 971-976.

67 D. Martínez-Matamoros, S. Castro-García, M. Balado, A. Matamoros-Veloza, M. A. Camargo-Valero, O. Cespedes, J. Rodríguez, M. L. Lemos and C. Jiménez, RSC Adv., 2019, 9, 13533-13542.

68 A. Sobhan, J. Lee, M.-K. Park and J.-H. Oh, Lebensm.-Wiss. Technol., 2019, 108, 48-54.

69 S. Savas and Z. Altintas, Materials, 2019, 12, 2189.

70 Y. Li, H. Su and Y. Lan, J. AOAC Int., 2019, 101, 1833-1838.

71 F. Fois, F. Piras, M. Torpdahl, R. Mazza, D. Ladu, S. G. Consolati, C. Spanu, C. Scarano and E. P. L. De Santis, Int. J. Food Microbiol., 2018, 283, 1-6.

72 M. A. Stachelska, Pol. J. Microbiol., 2018, 67, 219-222.

73 P. Raymond, E. Houard, M. Denis and E. Esnault, MicrobiologyOpen, 2018, e751.

74 L. A. Rusak, R. de Castro Lisboa Pereira, I. G. Freitag, C. B. Hofer, E. Hofer, M. D. Asensi and D. C. Vallim, J. Microbiol. Methods, 2018, 154, 107-111.

75 T. Wielkoszynski, A. Moghaddam, A. Bäckman, J. Broden, R. Piotrowski, R. Mond-Paszek, A. Kozarenko, T. Ny and M. Wilczynska, Eur. J. Clin. Microbiol. Infect. Dis., 2018, 37, 2301-2306.

76 A. Rohde, J. A. Hammerl, B. Appel, R. Dieckmann and S. Al Dahouk, Food Microbiol., 2017, 62, 39-45.

77 M. A. Stachelska, Pol. J. Vet. Sci., 2017, 20, 477-484. 
78 M. C. Thomas, T. W. Janzen, G. Huscyzynsky, A. Mathews and K. K. Amoako, Int. J. Food Microbiol., 2017, 257, 247-253.

79 F. Koch, C. Wiacek and P. G. Braun, Int. J. Food Microbiol., 2019, 292, 64-71.

80 J. W. Jun, S. C. Park, A. Wicklund and M. Skurnik, Int. J. Food Microbiol., 2018, 271, 33-47.

81 H. Wang, M. Tay, J. Palmer and S. Flint, Food Control, 2017, 73, 433-437.
82 S. Bonardi, I. Bruini, M. D'Incau, I. Van Damme, E. Carniel, S. Brémont, P. Cavallini, S. Tagliabue and F. Brindani, Int. J. Food Microbiol., 2016, 235, 125-132.

83 K. A. Lis, C. Kehrenberg, A. Boulaaba, M. von KöckritzBlickwede, S. Binder, Y. Li, J. L. Zimmermann, Y. Pfeifer and B. Ahlfeld, Int. J. Antimicrob. Agents, 2018, 52, 811818. 